\title{
Local crystal structure and physical properties change of p-type transparent conducting oxide: $\mathrm{CuCrO}_{2}$ upon Ti-substitution
}

M. K. Majee, P. A. Bhobe, U. P. Deshpande, and A. K. Nigam

Citation: Journal of Applied Physics 122, 225111 (2017);

View online: https://doi.org/10.1063/1.5003965

View Table of Contents: http://aip.scitation.org/toc/jap/122/22

Published by the American Institute of Physics

\section{Articles you may be interested in}

Electrical transport and optical band gap of $\mathrm{NiFe}_{2} \mathrm{O}_{\mathrm{X}}$ thin films

Journal of Applied Physics 122, 225101 (2017); 10.1063/1.4999428

Multiple electrical phase transitions in Al substituted barium hexaferrite

Journal of Applied Physics 122, 224106 (2017); 10.1063/1.4998719

A structural-electrical property correlation in A-site double substituted lanthanum aluminate Journal of Applied Physics 122, 225106 (2017); 10.1063/1.4999002

Improvement of gas-sensing performance of $\mathrm{ZnO}$ nanorods by group-I elements doping

Journal of Applied Physics 122, 224505 (2017); 10.1063/1.5009249

Enhanced performance of ferroelectric materials under hydrostatic pressure

Journal of Applied Physics 122, 224105 (2017); 10.1063/1.5003775

Phase-field modeling and electronic structural analysis of flexoelectric effect at $180^{\circ}$ domain walls in ferroelectric $\mathrm{PbTiO}_{3}$

Journal of Applied Physics 122, 224101 (2017); 10.1063/1.5017219

\section{Scilight}

Sharp, quick summaries illuminating the latest physics research

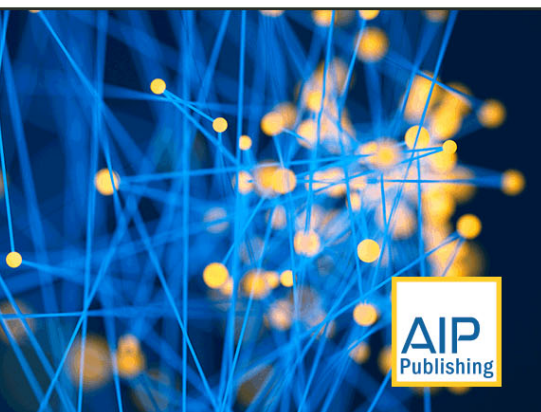




\title{
Local crystal structure and physical properties change of $p$-type transparent conducting oxide: $\mathrm{CuCrO}_{2}$ upon Ti-substitution
}

\author{
M. K. Majee, ${ }^{1}$ P. A. Bhobe, ${ }^{1, a)}$ U. P. Deshpande, ${ }^{2}$ and A. K. Nigam ${ }^{3}$ \\ ${ }^{1}$ Discipline of Physics, Indian Institute of Technology Indore, Khandwa Road, Simrol, Indore 453 552, India \\ ${ }^{2} U G C$-DAE Consortium for Scientific Research, University Campus, Khandwa Road, Indore 452 017, India \\ ${ }^{3}$ Tata Institute of Fundamental Research, Homi Bhabha Road, Mumbai 400005 , India
}

(Received 9 September 2017; accepted 20 November 2017; published online 12 December 2017)

A combination of high optical transparency and good electrical conductivity is realized in $\mathrm{CuCrO}_{2}$, a $p$-type transparent conducting oxide. With an aim to improve its physical properties, a $\mathrm{CuCr}_{1-x} \mathrm{Ti}_{x} \mathrm{O}_{2}(x=0,0.05,0.1)$ series was prepared and investigated for its structural, electrical transport, and optical properties. Along with the lattice parameter values, refinement of X-ray diffraction profiles confirm the solubility limit of Ti within the delafossite unit cell. Electrical resistivity and heat capacity measured by varying the temperature further characterize the Ti-substituted compositions. As determined from ultraviolet-visible spectroscopy, no significant changes take place in the optical gap of $\mathrm{CuCrO}_{2}$ with Ti addition. Apart from confirming the $4+$ valence state of $\mathrm{Ti}$, the $\mathrm{X}$-ray absorption near edge structure highlights the subtle changes taking place in the $\mathrm{Cu}-\mathrm{O}$ hybridization upon Ti-substitution. The analysis of temperature dependent extended X-ray absorption fine structure spectroscopy, recorded at the $\mathrm{Cr}$ and $\mathrm{Cu} \mathrm{K}$-edge, emphasizes the impact of redistribution of charges on the local crystal structure. $\mathrm{Cu}-\mathrm{Cu}$ hybridization along the $a$-axis appears to be influenced mainly by the temperature and only slightly by Ti substitution. Published by AIP Publishing. https://doi.org/10.1063/1.5003965

\section{INTRODUCTION}

One of the prime areas of research in the rapidly expanding semiconductor industry is the development of metal oxide based transparent electronics. In fact, oxide materials have surpassed the applicability of silicon in certain domains, and new industry standards are set by materials like indium tin oxide and its substitutional variants. ${ }^{1,2}$ The development of an entirely feasible device, however, requires both $n$ and $p$-type oxides that can be easily integrated with the existing largescale manufacturing technology. In practice, as compared to the $n$-type oxides, there have been a limited number of $p$-type materials with sufficiently high mobility and suitable band structure. ${ }^{3}$ A few Cr-based oxides such as $\mathrm{Mg}$-doped $\mathrm{Cr}_{2} \mathrm{O}_{3}{ }^{4}{ }^{4}$ Sr-doped $\mathrm{LaCrO}_{3},{ }^{5}$ and $\mathrm{Li}$-doped $\mathrm{Cr}_{2} \mathrm{MnO}_{4}{ }^{6}$ have been discussed to constitute this emerging class of $p$-type Transparent Conducting Oxides (TCOs).

$\mathrm{CuCrO}_{2}$ is one such TCO with a direct band gap of $3.1-3.35 \mathrm{eV}^{7,8}$ It belongs to the delafossite family of compounds, generally known for its large unit cell and layered structure, and described by space group $R \overline{3} m$ in the hexagonal setting. These compounds are represented by the general chemical formula, $\mathrm{ABO}_{2}$. The $\mathrm{B}$ cations form layers of edgeshared $\mathrm{BO}_{6}$ octahedra in the $a b$ plane, stacked along the $c$-axis and connected via the O-A-O linear chains. For the $\mathrm{CuCrO}_{2}$ composition, the $\mathrm{Cu}^{1+}$ ions constitute the filled $3 \mathrm{~d}^{10}$ orbitals and form linear chains along the $c$-axis. The magnetic $\mathrm{Cr}^{3+}$ ions $\left(3 \mathrm{~d}^{3}, \mathrm{t}_{2 g}^{3}\right)$ present within the $\mathrm{CrO}_{6}$ octahedra constitute a triangular lattice in the $a b$ plane that interacts antiferromagnetically (AF) with an ordering temperature

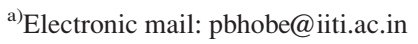

$\mathrm{T}_{N} \sim 24 \mathrm{~K} .{ }^{9}$ Besides being a candidate material for TCO, $\mathrm{CuCrO}_{2}$ has been actively pursued for its multiferroic properties. For example, the dilution of the magnetic sublattice of $\mathrm{CuCrO}_{2}$ with nonmagnetic ions like Sc, $\mathrm{Rh}, \mathrm{Ga}$, and $\mathrm{Al}$, and its effect on electric polarization is reported in Ref. 10. The change in the magnetic ground state by substitution of $\mathrm{Cr}$ with other transition metal ions like $\mathrm{Ni}, \mathrm{Rh}$, and $\mathrm{Mn}$ has been investigated by Refs. 11-13. Other non Cr-based delafossite oxides like $\mathrm{CuScO}_{2}, \mathrm{CuLaO}_{2}, \mathrm{CuInO}_{2}$, and $\mathrm{CuAlO}_{2}$ also display unusual structural properties, for instance, negative thermal expansion of the unit cell. ${ }^{14,15}$

To improve the transparency and $p$-type conductivity of $\mathrm{CuCrO}_{2}$, various studies have been carried out by substituting different valence cations at the $\mathrm{Cr}$-site. One such example is the increase in electrical conductivity achieved through the introduction of holes by replacing $5 \% \mathrm{Cr}^{3+}$ ions by $\mathrm{Mg}^{2+}$ in Refs. 16 and 17. Another study reports the crystal and magnetic properties of Ti substitution at the $\mathrm{Cr}^{3+}$ site, ${ }^{18}$ claiming Ti to adopt a $2+$ state, whereas $\mathrm{Li}$ et al. reports a strong resistive relaxation behavior in $\mathrm{CuCr}_{1-x} \mathrm{Ti}_{x} \mathrm{O}_{2}$ and argues that it is $\mathrm{Ti}^{4+}$ that substitutes the $\mathrm{Cr}^{3+}$ site, leading to a significant increase in the resistivity due to the diminishing conducting holes. ${ }^{19}$ Hence, it becomes pertinent to re-visit such a study and clarify the valence state and its impact on the interesting properties of this important delafossite composition.

With this aim, we investigated the local crystal structure as well as the electrical and optical properties of $\mathrm{CuCr}_{1-x}$ $\mathrm{Ti}_{x} \mathrm{O}_{2}$. A comprehensive analysis of the crystal structure using room temperature powder X-ray diffraction (XRD) and temperature dependent extended X-ray absorption finestructure (EXAFS) spectroscopy at the $\mathrm{Cu}$ and $\mathrm{Cr}$ K-edge 
has been performed here. These results are viewed in the perspective of the electrical and optical properties measured using temperature dependent four-probe resistivity, heat capacity, and ultraviolet-visible (UV-Vis) spectroscopy for all the studied compositions.

\section{EXPERIMENTAL DETAILS}

Polycrystalline samples of $\mathrm{CuCr}_{1-x} \mathrm{Ti}_{x} \mathrm{O}_{2}$ (with $x=0$, $0.05,0.1$ ) were prepared using the standard solid state reaction method. Stoichiometric amounts of the starting oxides (99.99\% purity), viz., $\mathrm{Cu}_{2} \mathrm{O}, \mathrm{Cr}_{2} \mathrm{O}_{3}$, and $\mathrm{TiO}_{2}$, were mixed thoroughly, pelletized, and calcined in air at a temperature of $1000{ }^{\circ} \mathrm{C}$ for $12 \mathrm{~h}$. These pellets were re-ground, re-pelletized, and annealed in air at $1200^{\circ} \mathrm{C}$ for another $12 \mathrm{~h}$. Powder XRD profiles of the samples so obtained were recorded in the range of $10^{\circ}-80^{\circ}$, using a RIGAKU SMARTLAB diffractometer equipped with a monochromatic $\mathrm{Cu} \mathrm{K} \alpha(\lambda=1.541 \AA)$ source. The XRD patterns were analyzed by the Rietveld refinement technique using the FULLPROF suite. ${ }^{20}$ The heat capacity of all the three samples was recorded as a function of temperature in the range of 5-300 K using a physical properties measurement system (PPMS) by Quantum Design, Inc. Further, the temperature dependence of four probe electrical resistivity was measured using PPMS in the range of $200-380 \mathrm{~K}$. Below $200 \mathrm{~K}$, the rise in resistance was beyond the measurable range of the instrument. Room temperature UV-Vis diffusion reflectance spectroscopy was carried out using the Perkin-Elmer lambda 950 spectrometer, in the wavelength range of $200-800 \mathrm{~nm}$.

EXAFS was recorded at the undulator beamline P65 of PETRAIII, DESY, Hamburg. The experiments were performed in the transmission mode at the Cr K-edge $(5989 \mathrm{eV})$ and $\mathrm{Cu}$ K-edge $(8979 \mathrm{eV})$. The incident and transmitted intensities were measured using gas-filled ionization chamber detectors. The absorber thickness was adjusted to restrict the absorption edge jump $(\Delta \mu)$ to an optimum value. Multiple identical spectra were acquired and averaged to improve the signal-to-noise ratio. The spectra were recorded at 10,100 , and $300 \mathrm{~K}$, spanning the magnetic order-disorder transition in $\mathrm{CuCr}_{1-x} \mathrm{Ti}_{x} \mathrm{O}_{2}$. Data reduction and analysis were carried out using the DEMETER suite. ${ }^{21}$ Fitting was carried out by extracting the data in the k-range of (2-13.25) $\AA^{1}$ Room temperature Ti K-edge X-ray absorption near edge spectroscopy (XANES) was recorded in the fluorescence mode at the BL-09, INDUS-2 synchrotron source, RRCAT, Indore.

\section{RESULTS AND DISCUSSION}

Room temperature XRD patterns for the prepared samples of $\mathrm{CuCr}_{1-x} \mathrm{Ti}_{x} \mathrm{O}_{2}$ (with $x=0,0.05,0.1$ ) are presented in Fig. 1. All the observed peaks are indexed to a layered $2 H$ delafossite structure with $R \overline{3} m$ space group with $\mathrm{Cu}$ at $3 a(0,0,0), \mathrm{Cr}$ at $3 b(0,0,1 / 2)$, and $\mathrm{O}$ at $6 c(0,0, z)$ sites. Given that the lattice constant along the $c$-axis of a delafossite unit cell is generally quite large in comparison to its $a$-axis, certain peaks representing the reflections along the $c$-axis are unusually high in intensity. The lattice parameter values obtained after Rietveld refinement of the XRD profile of

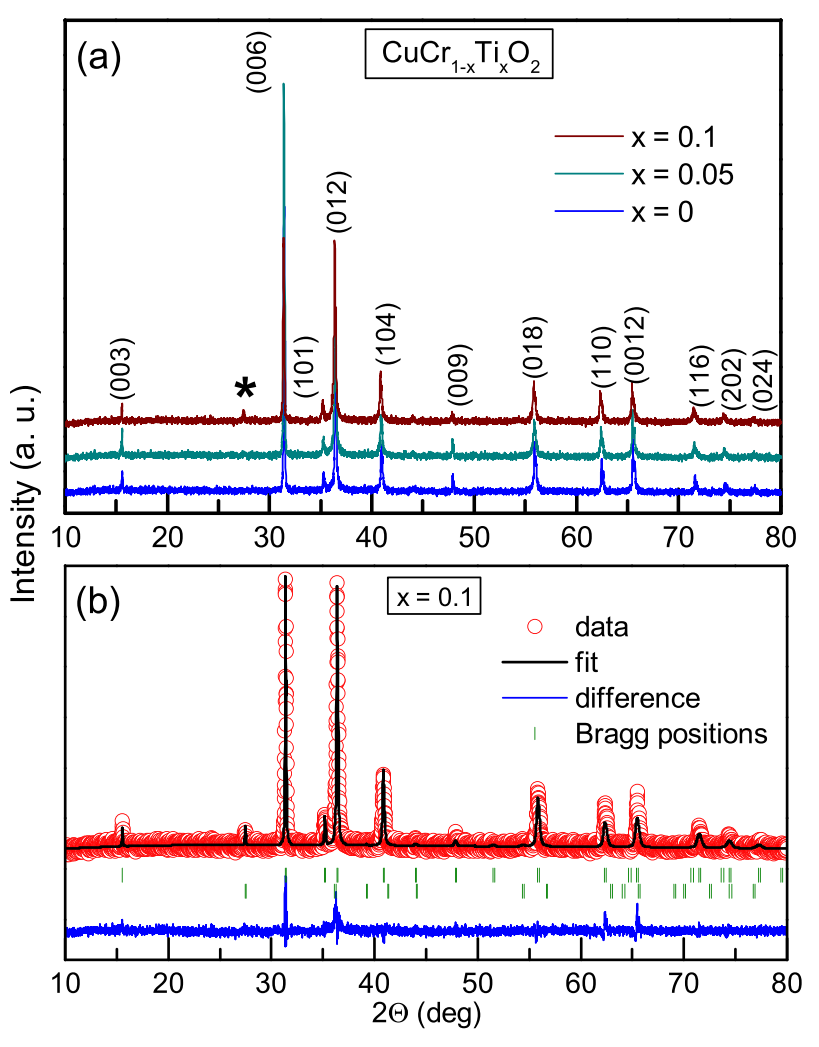

FIG. 1. (a) Powder XRD patterns for $\mathrm{CuCr}_{1-x} \mathrm{Ti}_{x} \mathrm{O}_{2}$. The peak labeled with ( $\star$ ) belongs to the $\mathrm{TiO}_{2}$ phase. (b) Two-phase Rietveld refinement fit for the XRD pattern of $x=0.1$. The typical values of goodness-of-fit parameters, Bragg $R$-factor $=8.96 \%, R_{w p}=10.5 \%, R_{\text {expected }}=8.81 \%$, and $\chi^{2}=1.91$.

$\mathrm{CuCrO}_{2}$ are $a=2.971(8) \AA$ and $c=17.074(5) \AA$, in accordance with the reported values in literature. ${ }^{22} \mathrm{As} \mathrm{Ti}$ is doped at the Cr-site, a normal expansion of the unit cell is observed along the $c$-axis, while the change in $a$ is within error bars. The lattice constant values for $x=0.05$ and 0.1 are $a=2.974(8) \AA ; 2.977(5) \AA$ and $c=17.087(9) \AA ; 17.103(5) \AA$, respectively. In the case of $x=0.1$, an extra peak appears at $2 \theta=27.4^{\circ}$ that was identified as the rutile $\mathrm{TiO}_{2}$ phase. The corresponding XRD profile was thus refined including $\mathrm{TiO}_{2}$ as a second phase and upon refinement, it turned out to constitute only $\sim 3.5 \%$ of the total phase. So, out of the total substitution of $10 \% \mathrm{Ti}$, we expect $\sim 9.7 \%$ to form the delafossite phase, and remaining $\sim 0.3 \%$ contributes to the formation of $\mathrm{TiO}_{2}$. We continue to refer to this $10 \%$ composition as $x=0.1$. The appearance of the $\mathrm{TiO}_{2}$ peak is an indication that solubility of Ti in the parent compound is limited to $x \leq 0.1$ and any further substitution would not yield a single phase material.

$\mathrm{CuCrO}_{2}$ displays a complex magnetic nature with competing antiferromagnetic (AF) and ferromagnetic (FM) Heisenberg exchange interactions. ${ }^{23,24}$ Its delafossite unit cell consists of edge-shared $\mathrm{CrO}_{6}$ octahedra. A frustrated AF triangular lattice is formed by direct interaction between $\mathrm{Cr}^{3+}$ ions in the $2 \mathrm{D}$ plane, whereas the $90^{\circ} \mathrm{Cr}^{3+}-\mathrm{O}^{2-}-\mathrm{Cr}^{3+}$ interactions result in FM interactions. The competition between these interactions is delicately balanced by the overlap of orbitals in the unit cell. With the introduction of nonmagnetic $\mathrm{Ti}$ at the $\mathrm{Cr}$ site, the lattice parameters are seen to increase, affecting the $\mathrm{Cr}-\mathrm{Cr}$ and $\mathrm{Cr}-\mathrm{O}$ orbital overlap. The signatures of such competition are reflected in the measured 
magnetic properties of $\mathrm{Ti}$ substituted compositions. A detailed study of the magnetic properties of $\mathrm{CuCr}_{1-x} \mathrm{Ti}_{x} \mathrm{O}_{2}$ (with $x=0,0.05,0.1$ ) has earlier been reported by us, ${ }^{25}$ and hence briefly discussed here.

Previous neutron scattering studies ${ }^{26}$ report $\mathrm{AF}$ ordering of $\mathrm{CuCrO}_{2}$ with a $\mathrm{T}_{N} \sim 25 \mathrm{~K}$. Accordingly, the magnetic properties measured for our sample of $\mathrm{CuCrO}_{2}$ also shows AF order with a $\mathrm{T}_{N} \sim 24 \mathrm{~K}$. The high temperature region of $1 / \chi_{D C}$ vs. T obeys the Curie-Weiss law $\left[\chi=\mathrm{C} /\left(\mathrm{T}+\Theta_{w}\right)\right]$, with deviation from linearity below $\sim 150 \mathrm{~K}$, reflecting the presence of underlying short-range $\mathrm{AF}$ interactions long before the system orders magnetically. The paramagnetic moment extracted from the fit, $\mu_{\text {para }} \sim 3.92 \mu_{B}$, is close to the theoretical estimate of $\mathrm{Cr}^{3+}=3.87 \mu_{B}$. Ti substitution alters the magnetization $[\mathrm{M}(\mathrm{T})]$ curve with no sharp or clear feature signaling an AF transition. Rather, the $x=0.05$ shows a highly diffused ferromagnetic-like hump over a broad transition region, and a slight drop in $\mathrm{M}(\mathrm{T})$ at $\sim 20 \mathrm{~K}$. No clear $\mathrm{AF}$ transition is seen for $x=0.1$, except for a small kink-like feature at $\sim 15 \mathrm{~K}$.

The heat capacity measured as a function of temperature for $\mathrm{CuCr}_{1-x} \mathrm{Ti}_{x} \mathrm{O}_{2}$ and presented in Fig. 2 complements the magnetic properties discussed above. $\mathrm{CuCrO}_{2}$ displays a sharp $\lambda$-type anomaly at $\mathrm{T}_{N}$. This anomaly is considerably broadened and gets systematically shifted towards low temperatures for Ti-substituted compositions. It has been reported that a non-magnetic substituent like $\mathrm{Mg}^{2+}$ at the $\mathrm{Cr}$ site in $\mathrm{CuCrO}_{2}$ is known to make the peak at $\mathrm{T}_{N}$ sharper and shift it towards a higher temperature. ${ }^{27}$ They attribute such behaviour to introduction of holes by $\mathrm{Mg}^{2+}$ that enhance the spin fluctuations at the Cr-site. Contrary to such observation, the present data do not seem to signal the introduction of holes in $\mathrm{CuCr}_{1-x} \mathrm{Ti}_{x} \mathrm{O}_{2}$. In other words, $\mathrm{Ti}$ substituted in $\mathrm{CuCr}_{1-x} \mathrm{Ti}_{x} \mathrm{O}_{2}$ cannot be assumed to be in the $2+$ state, as reported in Ref. 18.

To understand the role played by Ti-substitution on the electrical properties of $\mathrm{CuCrO}_{2}$, we carried out electrical resistivity measurements as a function of temperature. Figure 2 shows the resistivity $(\rho)$ measured while warming the samples for $200-380 \mathrm{~K}$. Reflecting its semiconducting nature, the resistivity for all three samples seems to fall with the rising temperature. The $\rho(\mathrm{T})$ curves of our samples are comparable to those of single crystalline, as well as polycrystalline materials previously reported in literature. ${ }^{28}$ The thermal activation energies $\left(\mathrm{E}_{a}\right)$ extracted for these compositions are $0.34 \mathrm{eV}, 0.29 \mathrm{eV}$, and $0.28 \mathrm{eV}$ for $x=0,0.05$, and 0.1 , respectively. A decrease in the activation energy with Tisubstitution indicates introduction of in-gap states in $\mathrm{CuCrO}_{2}$. However, it is also noticed that the electrical resistivity for Ti doped samples saturates at temperatures higher than the parent $\mathrm{CuCrO}_{2}$. In other words, though the thermal energy needed to activate the charge carriers across the gap reduced, the overall conduction itself has decreased with Tisubstitution. Putting both these aspects together, one can attempt to interpret an eventual decrease in the carrier concentration taking place, with higher valence Ti ions replacing the $\mathrm{Cr}^{3+}$ ions. This argument is further supported by the drastic decrease in resistivity brought about by lower valence $\mathrm{Mg}^{2+}$ substitution in $\mathrm{CuCr}_{1-x} \mathrm{Mg}_{x} \mathrm{O}_{2},{ }^{28}$ and reinforces our inference that the $2+$ valence state for $\mathrm{Ti}$ ions is unlikely in the $\mathrm{CuCr}_{1-x} \mathrm{Ti}_{x} \mathrm{O}_{2}$ series.

To clarify the impact of Ti-substitution on the optical properties of $\mathrm{CuCrO}_{2}$, we investigated the $\mathrm{CuCr}_{1-x} \mathrm{Ti}_{x} \mathrm{O}_{2}$ series for its optical absorbance. $\mathrm{CuCrO}_{2}$ belongs to the
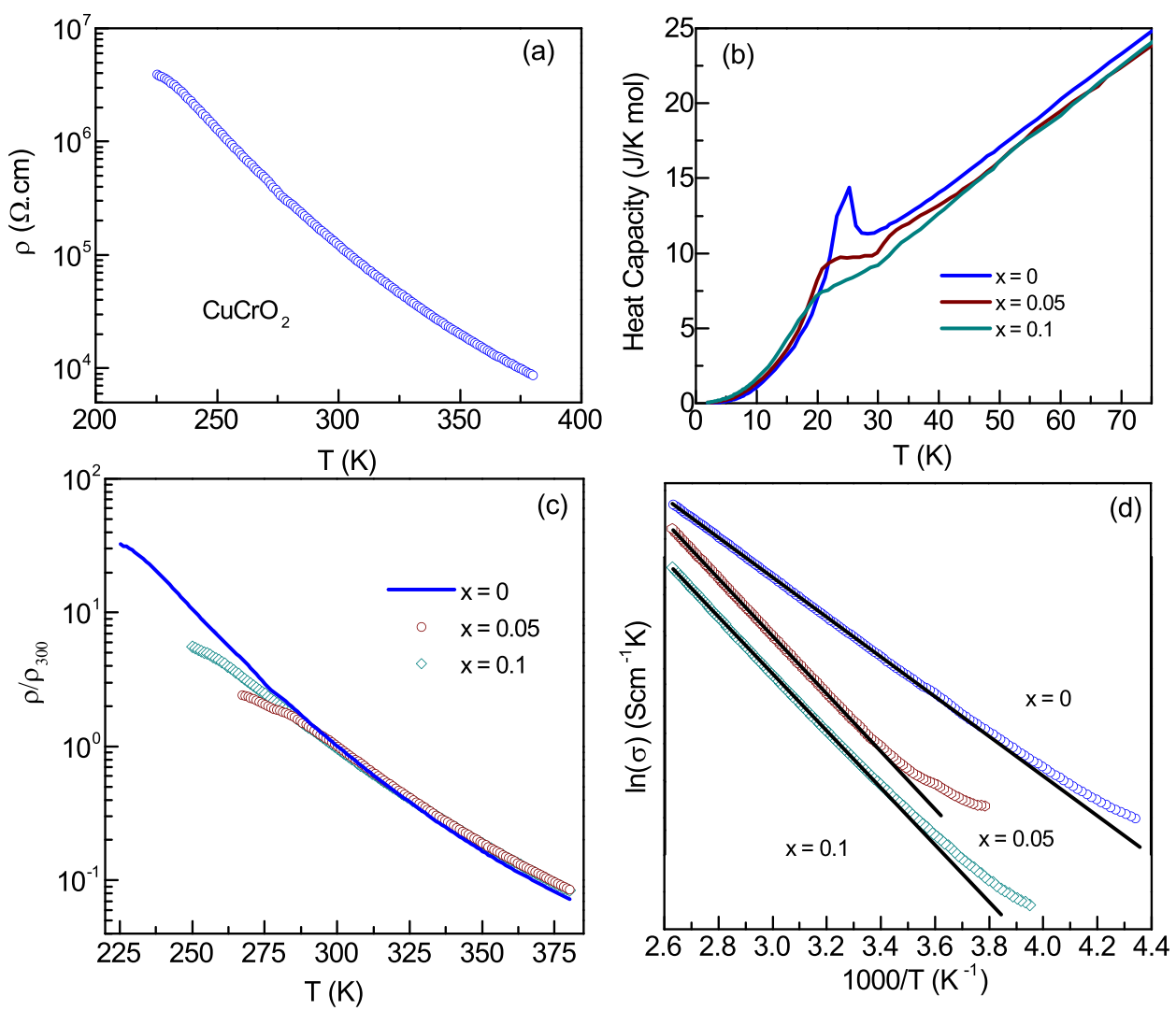

FIG. 2. (a) Plot of resistivity as a function of temperature for $\mathrm{CuCrO}_{2}$, (b) temperature dependent specific heat for $\mathrm{CuCr}_{1-x} \mathrm{Ti}_{x} \mathrm{O}_{2}$, (c) comparison of normalized resistivity for all the prepared samples, and (d) activation energy fit to the conductivity (1/resistivity) for all samples. The solid line is the fit to the data. The plots have been offset along the $y$-axis for clear presentation. 


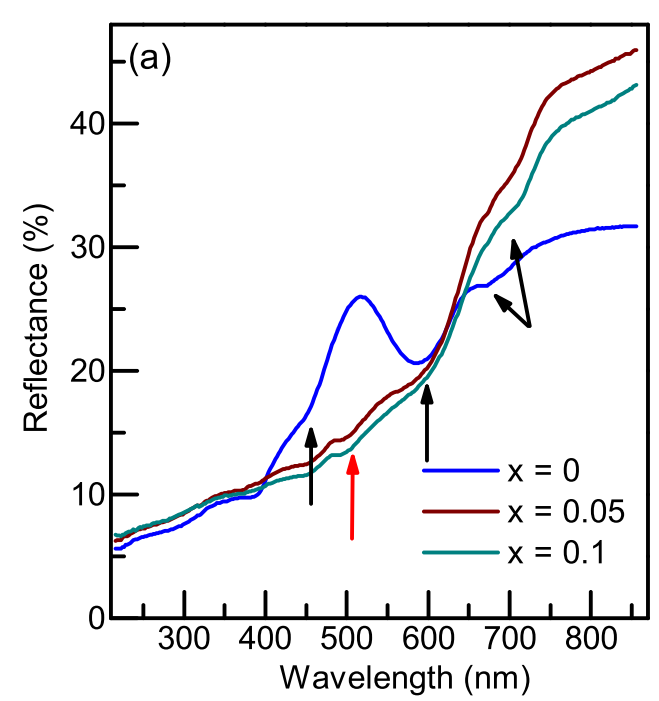

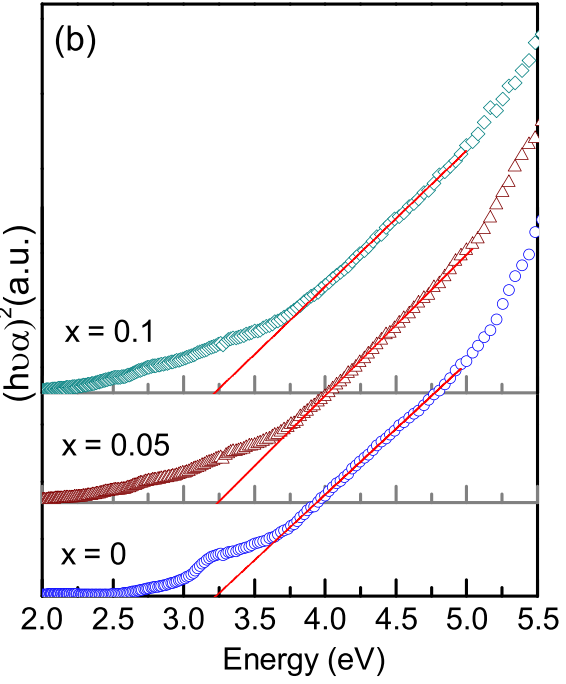

FIG. 3. (a) UV-Vis reflectance spectra for the $\mathrm{CuCr}_{1-x} \mathrm{Ti}_{x} \mathrm{O}_{2}$ series, measured at room temperature. The arrows indicate the transitions as described in the text. (b) Solid line fit to the plot of $(h \nu \alpha)^{2} v s$. photon energy. The intercept determines the optical band gap. family of transparent conducting oxides and has a high absorption coefficient in the UV region. According to the first principle calculations, ${ }^{29}$ the optical excitation takes place across $\mathrm{Cu} 3 d+\mathrm{O} 2 p \rightarrow \mathrm{Cu} 3 d_{z^{2}}+4 s$ with an absorption energy $\mathrm{E}_{g}=3.2 \mathrm{eV}$, whereas the occupied $\mathrm{t}_{2 g}$ and the empty $\mathrm{e}_{g}$ bands of $\mathrm{Cr}^{3+}$ are energetically away from the valence band maximum and conduction band minimum. The optical absorbance spectra for the $\mathrm{CuCr}_{1-x} \mathrm{Ti}_{x} \mathrm{O}_{2}$ series was hence obtained in the wavelength range of 200 to $800 \mathrm{~nm}$ and the corresponding plots are shown in Fig. 3. The optical band-gap was deduced using Tauc's relation, ${ }^{30}(\alpha \mathrm{h} \nu)^{n}=\mathrm{A}\left(\mathrm{h} \nu-\mathrm{E}_{g}\right)$, as shown in Fig. 3. Here, $(\mathrm{h} \nu)$ is the photon energy, $\mathrm{A}$ is a constant, and $\mathrm{E}_{g}$ is the band gap. The parameter $n$ is set to a value of 2 for materials with a direct band-gap. The gap extracted from such an analysis is found to vary from $3.24 \mathrm{eV}$ for $x=0$ to $3.21 \mathrm{eV}$ for $x=0.1$. Similar values of $\mathrm{E}_{g}$ for $\mathrm{CuCrO}_{2}$ have been reported in literature for polycrystalline $(\approx 3.35 \mathrm{eV})^{7}$ and thin films $(\approx 3.2 \mathrm{eV}){ }^{31}$ Thus, the small variation in $\mathrm{E}_{g}$ seen with Ti-substitution indicates a very subtle change in the $\mathrm{Cu}-\mathrm{O}$ hybridization.

Besides the optical gap, the absorbance spectrum for $\mathrm{CuCrO}_{2}$ shows additional features at $2.12 \mathrm{eV}(585 \mathrm{~nm})$ and $1.85 \mathrm{eV}(670 \mathrm{~nm})$ that are distinct signatures associated with ligand field excitations of octahedrally coordinated $\mathrm{Cr}^{3+}$ ions. ${ }^{32}$ The $\mathrm{Cr}^{3+}$ ions have a ${ }^{4} A_{2 g}$ ground state with two low lying spin allowed excitations derived from ${ }^{4} T_{2 g}$ and ${ }^{4} T_{1 g}$ states of the excited $t_{2 g} \mathrm{e}_{1 g}$ configuration. Thus, the low energy features at $2.12 \mathrm{eV}$ and $1.85 \mathrm{eV}$ in the present data-set are identified as the ${ }^{4} \mathrm{~A}_{2 g} \rightarrow{ }^{4} \mathrm{~T}_{1 g}\left({ }^{4} \mathrm{~F}\right)$ and ${ }^{4} \mathrm{~A}_{2 g} \rightarrow{ }^{4} \mathrm{~T}_{2 g}\left({ }^{4} \mathrm{~F}\right)$ transitions, respectively. With the substitution of $\mathrm{Ti}$, the absorption energies of these transitions shift to lower values and the sharp transition seen in $x=0$ also smoothens out. An extra absorption level at $2.53 \mathrm{eV}(491 \mathrm{~nm})$ is observed. To understand the origin of such an extra level, we need to reflect that a straightforward impact of substituting $\mathrm{Cr}^{3+}$ by $\mathrm{Ti}$ is the redistribution of valency vis-a-vis amongst the cations. In other words, to accommodate the substituted $\mathrm{Ti}$ which is likely to be in the $4+$ state, the hybridization of $\mathrm{Cr}^{3+}$ and/or $\mathrm{Cu}^{1+}$ with $\mathrm{O}^{2-}$ can change. Thus, direct evidence for the valence state of $\mathrm{Cu}, \mathrm{Cr}$, and $\mathrm{Ti}$ ions becomes important for understanding the electrical, as well as the magnetic properties of this material.
XANES spectra at the $\mathrm{Cu}, \mathrm{Cr}$, and $\mathrm{Ti} \mathrm{K}$-edge were recorded to confirm the valence state of these ions in the $\mathrm{CuCr}_{1-x} \mathrm{Ti}_{x} \mathrm{O}_{2}$ series. The plots are shown in Fig. 4. The Ti $\mathrm{K}$-edge recorded for $x=0.05$ and 0.1 compositions is shown in the bottom panel of Fig. 4 and found to match exactly with that of $\mathrm{TiO}_{2}$. Besides, some small pre-edge features due to dipole and quadruple excitation of $\mathrm{Ti}$ present in the octahedral coordination are also observed at the low binding energy side of the spectra confirming that Ti replaces the targeted $\mathrm{Cr}$-octahedral sites in $\mathrm{CuCr}_{1-x} \mathrm{Ti}_{x} \mathrm{O}_{2}$. The current spectra are experimental evidence confirming the $4+$ nature of $\mathrm{Ti}$ ions and discarding previous speculations ${ }^{18}$ of it being in the $2+$ valence state. Next, is the Cr K-edge spectra measured for all three compositions and displayed in the central panel

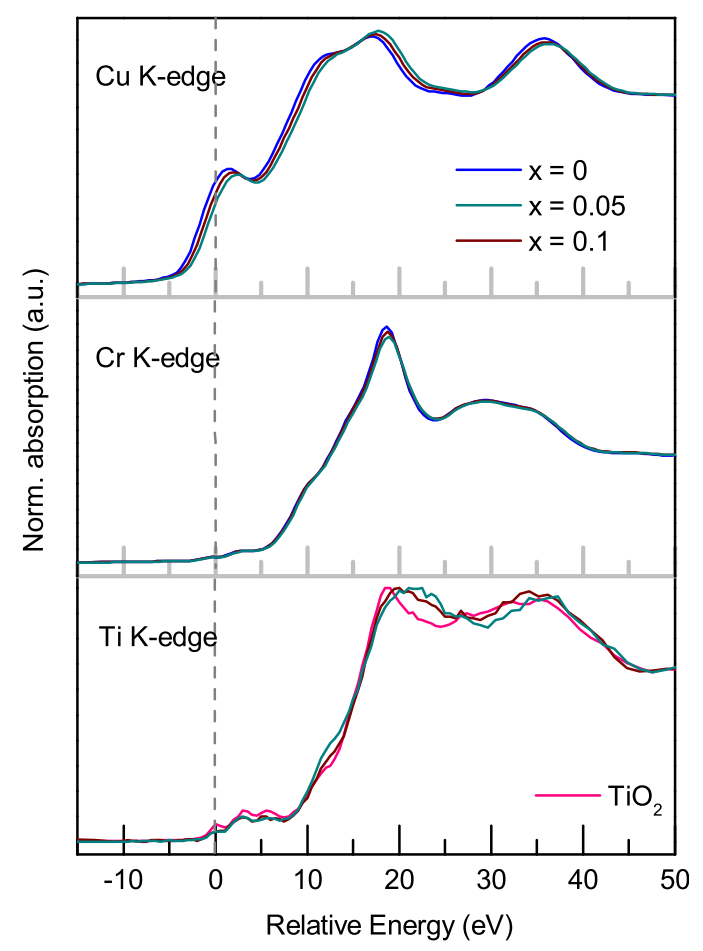

FIG. 4. XANES spectra for $\mathrm{CuCr}_{1-x} \mathrm{Ti}_{x} \mathrm{O}_{2}$ recorded at room temperature across the $\mathrm{Cu}, \mathrm{Cr}$, and $\mathrm{Ti} \mathrm{K}$-edge. The absorption edge energy along the $x$ axis is calibrated with respect to the corresponding pure metal edge energy. 

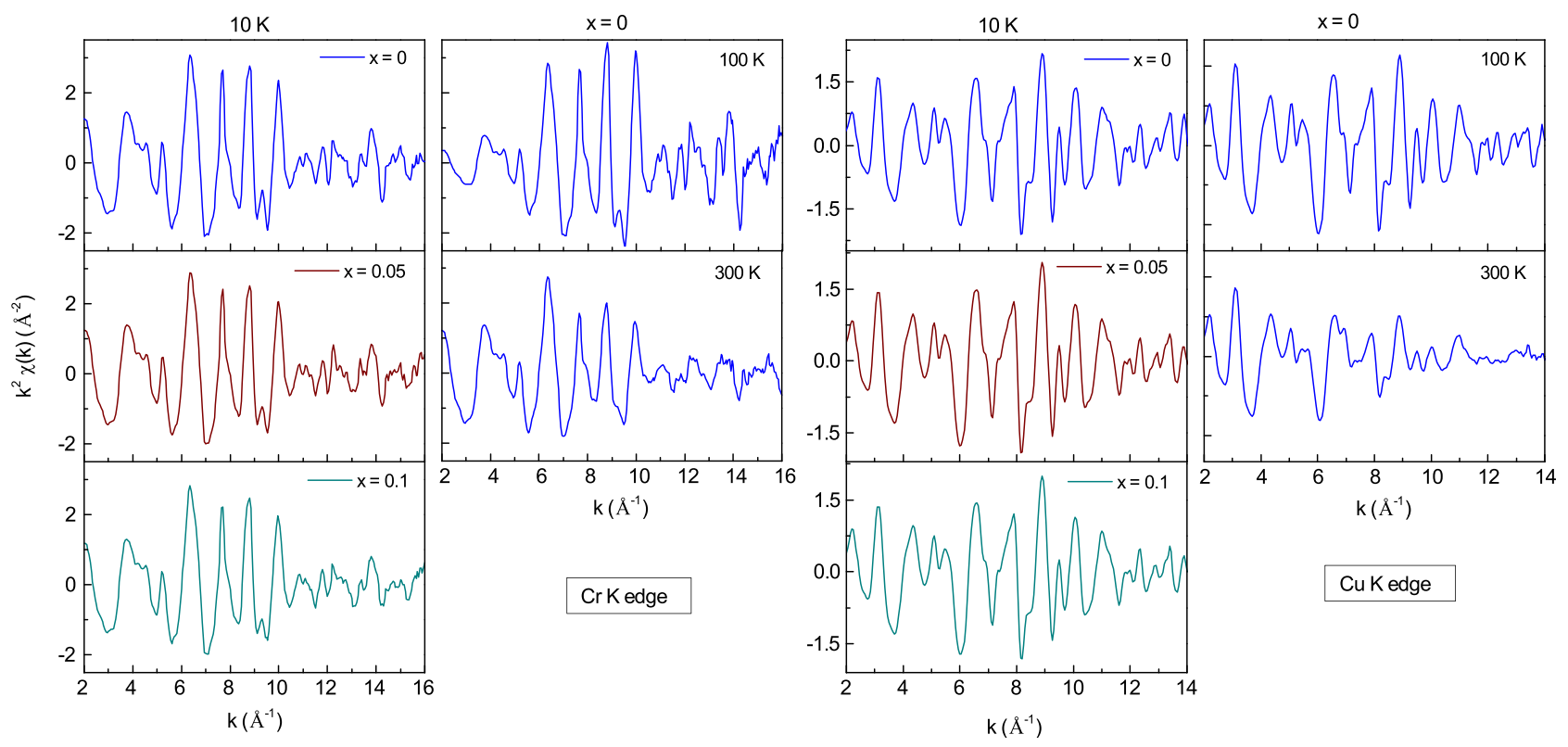

FIG. 5. $\mathrm{k}^{2}$ weighted raw EXAFS spectra recorded at the $\mathrm{Cr}$ and $\mathrm{Cu} \mathrm{K}$-edge for $\mathrm{CuCrO}_{2}$ at 10,100 , and $300 \mathrm{~K}$ and for $x=0,0.05$, and 0.1 at $10 \mathrm{~K}$. Selected spectra are presented here for clarity of the figure.

of Fig. 4. The absorption edge energy of these spectra are shifted to higher energy as compared to the $\mathrm{Cr}$-metal edge and found to match exactly with that of $\mathrm{Cr}_{2} \mathrm{O}_{3}$, a standard compound of chromium having a 3 +oxidation state. Further, no shift in energy is seen with the changing Ti content, confirming that $\mathrm{Cr}$ valence remains intact with increasing Ti-content. The top panel of Fig. 4, presenting the $\mathrm{Cu} \mathrm{K}$ edge spectra, suggests that $\mathrm{Cu}$ is in the $1+$ oxidation state as the edge energy is shifted to the higher energy side of $\mathrm{Cu}$ metal. Although the formal valence state of $\mathrm{Cu}$ ions does not cross over to $2+$, as the absorption edge for $\mathrm{CuO}$, an oxide of copper with a $2+$ valence state is at least $5 \mathrm{eV}$ higher than the pure $\mathrm{Cu}-$ metal. ${ }^{33}$ However, we observe a slight shift ( $\sim 0.7 \mathrm{eV}$ each) towards higher energy with increasing Ticontent. This slight change in absorption energy, though not an indication of any significant oxidation of $\mathrm{Cu}$ ions, suggests that subtle changes in the electronic structure of $\mathrm{CuCrO}_{2}$ take place with $\mathrm{Ti}$ addition.

Alternatively, to accommodate the electronic charge of substituted $\mathrm{Ti}^{4+}$ ions, the hybridization of $\mathrm{Cu}^{1+}$ with $\mathrm{O}^{2-}$ can change, as no change in seen in the $\mathrm{Cr}^{3+}$ state. This argument is even more plausible when viewed from the perspective of the recent report on the electronic structure study of $\mathrm{CuCr}_{1-x} \mathrm{Mg}_{x} \mathrm{O}_{2}$ using photoemission spectroscopy (PES). ${ }^{34}$ In this study, Yokobori et al. observed two types of chargetransfer satellites attributed to $\mathrm{Cu}^{1+}\left(3 d^{10}\right)$ and $\mathrm{Cu}^{2+}\left(3 d^{9}\right)$ like initial states in the $\mathrm{Cu} 2 p-3 d$ resonant PES spectrum of $\mathrm{CuCrO}_{2}$, while their $\mathrm{Cu} 2 p$ core-level spectra reflect a $\mathrm{Cu}^{1+}$ character. They explain these seemingly contradictory results by proposing a finite $\mathrm{Cu}(3 d, 4 s)-\mathrm{Cr}(3 d)$ charge transfer via $\mathrm{O} 2 p$ states in the ground-state electronic configuration. In the context of the present results, since XANES records the excitation of photoelectron from the $1 s$-level to continuum, we are not able to capture such intricate atomic multiplets that are accessible to the energy level changes across $2 p-3 d$ transitions achieved using soft $\mathrm{x}$-rays. But, we do see the impact of such hybridization on the $\mathrm{Cu}-\mathrm{O}$ bond through EXAFS, as discussed below.

Further, EXAFS measurement was carried out at the $\mathrm{Cu}$ and $\mathrm{Cr} \mathrm{K}$-edge of all the $\mathrm{CuCr}_{1-x} \mathrm{Ti}_{x} \mathrm{O}_{2}$ samples, at 10, 100, and $300 \mathrm{~K}$, spanning its magnetic order-disorder phase. Raw EXAFS data in the form of $k^{2}$-weighted oscillations are presented in Fig. 5. The overall good quality of the signal allows us to choose the $k$ range from 2 to $13.25 \AA^{-1}$ for Fourier transforms. The modulus of Fourier transformed spectra are shown in Fig. 6. A cursory look at the plots in the lower panel of the figure tells us that Ti-substitution has a very weak effect on the local structure. Rather, temperature changes seem to affect the spectra more severely than the change in concentration, as clearly evident from the second peak feature of the $\mathrm{Cu}$-edge data (see the top right panel of Fig. 6). As per the crystal symmetry of $\mathrm{CuCrO}_{2}$, the $\mathrm{Cu}$ ions form linear bonds with $\mathrm{O}$ linking the $\mathrm{CrO}_{6}$ octahedra. Thus, the first correlation between 1.0 and $2.1 \AA$ for the $\mathrm{Cu}$ spectra

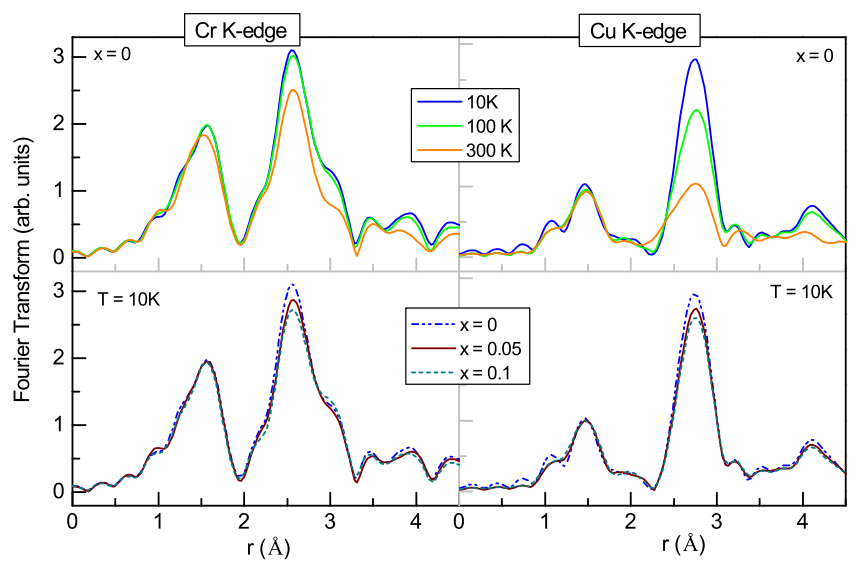

FIG. 6. $\mathrm{k}^{2}$ weighted Fourier transform spectra recorded at the $\mathrm{Cr}$ and $\mathrm{Cu}$ K-edge, top panel: at different temperatures and bottom panel: for different compositions. 
TABLE I. Results of the fits to the $\mathrm{Cr}$ and $\mathrm{Cu} \mathrm{K}$-edge EXAFS data of $\mathrm{CuCr}_{1-x} \mathrm{Ti}_{x} \mathrm{O}_{2}$. R refers to the bond length, and $\sigma^{2}$ is the thermal mean square variation in $\mathrm{R}$. The values inside parentheses indicate uncertainty in the last digit.

\begin{tabular}{|c|c|c|c|c|c|c|c|}
\hline \multirow{2}{*}{$\begin{array}{l}\text { Sample } \\
\text { Comp. }\end{array}$} & \multirow{2}{*}{$\begin{array}{l}\text { Atom and } \\
\text { Coord. no. }\end{array}$} & \multicolumn{2}{|c|}{$T=10 \mathrm{~K}$} & \multicolumn{2}{|c|}{$T=100 \mathrm{~K}$} & \multicolumn{2}{|c|}{$T=300 \mathrm{~K}$} \\
\hline & & $\mathrm{R}(\AA)$ & $\sigma^{2}\left(\AA^{2}\right)$ & $\mathrm{R}(\AA)$ & $\sigma^{2}\left(\AA^{2}\right)$ & $\mathrm{R}(\AA)$ & $\sigma^{2}\left(\AA^{2}\right)$ \\
\hline \multicolumn{8}{|c|}{ Cr K-edge } \\
\hline \multirow[t]{3}{*}{$x=0$} & $\mathrm{O} 1 \times 6$ & $1.974(6)$ & $0.0032(9)$ & $1.975(6)$ & $0.0032(8)$ & $1.972(5)$ & $0.0038(8)$ \\
\hline & $\mathrm{Cr} 1 \times 6$ & $2.984(5)$ & $0.0022(5)$ & $2.989(4)$ & $0.0023(5)$ & $2.994(5)$ & $0.0032(5)$ \\
\hline & $\mathrm{Cu} 1 \times 6$ & $3.334(8)$ & $0.0046(9)$ & $3.334(9)$ & $0.0051(9)$ & $3.331(13)$ & $0.0085(15)$ \\
\hline \multirow[t]{3}{*}{$x=0.05$} & $\mathrm{O} 1 \times 6$ & $1.975(5)$ & $0.0034(8)$ & $1.977(5)$ & $0.0035(8)$ & $1.976(4)$ & $0.0041(7)$ \\
\hline & $\mathrm{Cr} 1 \times 6$ & $2.983(4)$ & $0.0025(5)$ & $2.989(5)$ & $0.0025(5)$ & $2.996(4)$ & $0.0035(5)$ \\
\hline & $\mathrm{Cu} 1 \times 6$ & $3.331(8)$ & $0.0048(9)$ & $3.330(9)$ & $0.0054(5)$ & $3.326(12)$ & $0.0086(14)$ \\
\hline \multirow[t]{3}{*}{$x=0.1$} & $\mathrm{O} 1 \times 6$ & $1.978(5)$ & $0.0037(8)$ & $1.979(5)$ & $0.0038(8)$ & $1.980(5)$ & $0.0050(9)$ \\
\hline & $\mathrm{Cr} 1 \times 6$ & $2.988(5)$ & $0.0031(5)$ & $2.990(5)$ & $0.0031(5)$ & $2.999(5)$ & $0.0041(6)$ \\
\hline & $\mathrm{Cu} 1 \times 6$ & $3.334(7)$ & $0.0046(8)$ & $3.332(8)$ & $0.0052(9)$ & $3.331(12)$ & $0.0084(15)$ \\
\hline \multicolumn{8}{|c|}{$\mathrm{Cu}$ K-edge } \\
\hline \multirow[t]{5}{*}{$x=0$} & $\mathrm{O} 11 \times 1$ & $1.832(1)$ & $0.0021(14)$ & $1.833(1)$ & $0.0021(13)$ & $1.838(8)$ & $0.0024(11)$ \\
\hline & $\mathrm{O} 12 \times 1$ & $2.036(6)$ & $0.021(15)$ & $2.025(5)$ & $0.022(12)$ & $2.020(4)$ & $0.0250(11)$ \\
\hline & $\mathrm{Cu} 1 \times 6$ & $2.983(5)$ & $0.0056(5)$ & $2.985(6)$ & $0.0083(7)$ & $2.990(1)$ & $0.0169(17)$ \\
\hline & $\mathrm{Cr} 1 \times 6$ & $3.334(6)$ & $0.0046(6)$ & $3.334(5)$ & $0.0051(6)$ & $3.331(6)$ & $0.0088(9)$ \\
\hline & $\mathrm{O} 2 \times 12$ & $3.454(7)$ & $0.0034(11)$ & $3.459(6)$ & $0.0041(10)$ & $3.455(6)$ & $0.0096(14)$ \\
\hline \multirow[t]{5}{*}{$x=0.05$} & $\mathrm{O} 11 \times 1$ & $1.834(1)$ & $0.0020(13)$ & $1.838(1)$ & $0.0022(13)$ & $1.839(9)$ & $0.0023(11)$ \\
\hline & $\mathrm{O} 12 \times 1$ & $2.003(5)$ & $0.0201(11)$ & $2.008(4)$ & $0.0210(11)$ & $2.007(4)$ & $0.0231(46)$ \\
\hline & $\mathrm{Cu} 1 \times 6$ & $2.980(4)$ & $0.0061(5)$ & $2.989(6)$ & $0.0087(8)$ & 2.997(1) & $0.0173(19)$ \\
\hline & $\mathrm{Cr} 1 \times 6$ & $3.331(6)$ & $0.0048(7)$ & $3.330(6)$ & $0.0055(7)$ & $3.326(6)$ & $0.0086(9)$ \\
\hline & $\mathrm{O} 2 \times 12$ & $3.450(7)$ & $0.0052(11)$ & $3.456(7)$ & $0.0054(12)$ & $3.447(7)$ & $0.0101(15)$ \\
\hline \multirow[t]{5}{*}{$x=0.1$} & $\mathrm{O} 11 \times 1$ & $1.839(1)$ & $0.0020(16)$ & $1.837(2)$ & $0.0022(14)$ & $1.846(1)$ & $0.0023(15)$ \\
\hline & $\mathrm{O} 12 \times 1$ & $1.992(5)$ & $0.0211(11)$ & 1.984(4) & $0.0218(11)$ & $1.981(4)$ & $0.0225(40)$ \\
\hline & $\mathrm{Cu} 1 \times 6$ & $2.985(6)$ & $0.0069(5)$ & $2.987(8)$ & $0.0101(9)$ & $3.008(8)$ & $0.0181(25)$ \\
\hline & $\mathrm{Cr} 1 \times 6$ & $3.334(6)$ & $0.0046(7)$ & $3.332(6)$ & $0.0052(7)$ & $3.331(8)$ & $0.0084(11)$ \\
\hline & $\mathrm{O} 2 \times 12$ & $3.451(7)$ & $0.0048(13)$ & $3.446(8)$ & $0.0061(14)$ & $3.445(7)$ & $0.0107(17)$ \\
\hline
\end{tabular}

belongs to the $\mathrm{Cu}-\mathrm{O} 1$ bond. This is followed by $\mathrm{Cu}-\mathrm{Cu}$, $\mathrm{Cu}-\mathrm{Cr}$, and $\mathrm{Cu}-\mathrm{O} 2$, as the second, third, and, fourth coordination shells with $\mathrm{Cu}$ at the centre, in the range of 2.1 to $4 \AA$. Likewise, for Cr EXAFS (left panel of Fig. 6), the first correlation between 1 and $2 \AA$ is the $\mathrm{Cr}-\mathrm{O}$ bond with coordination number 6 , followed by $\mathrm{Cr}-\mathrm{Cr}$ and $\mathrm{Cr}-\mathrm{Cu}$ as the second and third coordination shells, respectively. Note that peak positions in Fig. 6 are not phase shift corrected and hence should not be assumed to appear at the absolute or actual bond distances extracted from the analysis as will be discussed later in the text. It may be noted that the $\mathrm{Cu}$ K-edge raw EXAFS oscillations, as well as the Fourier transformed spectra presented in Figs. 5 and 6, match very well with the previously reported $\mathrm{Cu}$ K-edge EXAFS of $\mathrm{CuScO}_{2}$ and $\mathrm{CuLaO}_{2}$ in Ref. 15.

With the crystal structure information like unit cell parameters and space group obtained from our XRD analysis, a careful quantitative analysis of EXAFS was performed. The model fit consisted of all direct scattering two-body correlations up to $4 \AA$ in $R$-space, as described in the preceding paragraph. The parameters like bond lengths and the corresponding thermal mean square variation $\left(\sigma^{2}\right)$ in the bond length were varied until a good fit was obtained. Other universal parameters like absorption edge energy corrections and scattering amplitude were obtained from fitting the data for $\mathrm{CuCrO}_{2}$ and maintained at similar values for Ti-substituted compositions. Final parameters obtained from an optimized fit are mentioned in Table I.
The fit to Cr EXAFS shows systematic variation in parameters and no drastic change or trend in $\mathrm{Cr}-\mathrm{O}$ and $\mathrm{Cr}-\mathrm{Cr}$ bonds, either with changing Ti-concentration or with temperature. In the light of magnetization results discussed previously, such plain systematics indicate that the change in magnetic properties that take place upon Ti-substitution in $\mathrm{CuCrO}_{2}$ is purely due to local defects created in the $\mathrm{Cr}$ spin lattice.

However, a striking distinction was observed during the analysis of Cu EXAFS. The first shell when fitted with the linear $\mathrm{Cu}-\mathrm{O} 1$ correlation with coordination number equal to 2 did not yield a good fit, resulting in a low value of bonddistance as high as $\sigma^{2}$. As depicted in Fig. 7(a), the amplitude of the fit to the feature at $1.0-2.1 \AA$ does not fit well with the data. Also, a phase mismatch between the data and the fit is seen, resulting in statistically poor fit-parameters. This issue is overcome by implementing two separate $\mathrm{Cu}-\mathrm{O}$ correlations, one long and one short, maintaining a total of $2 \mathrm{Cu}-\mathrm{O}$ bonds and seems to replicate the data quite well [see Fig. 7(b)]. Such an asymmetry in the first linear correlation of $\mathrm{Cu}$ ions that gives rise to a distribution of $\mathrm{Cu}-\mathrm{O}$ bonds is not a new feature to delafossites. In fact, a very detailed EXAFS analysis using the cumulant approach has been discussed in detail in Ref. 15 in the case of $\mathrm{CuScO}_{2}$ and $\mathrm{CuLaO}_{2}$, where the distribution in $\mathrm{Cu}-\mathrm{O}$ bond values has been highlighted. The rest of the correlations in the $2.1-4 \AA$ range, viz., $\mathrm{Cu}-\mathrm{Cu}, \mathrm{Cu}-\mathrm{Cr}$, and $\mathrm{Cu}-\mathrm{O} 2$, fit very well with the standard delafossite model. 


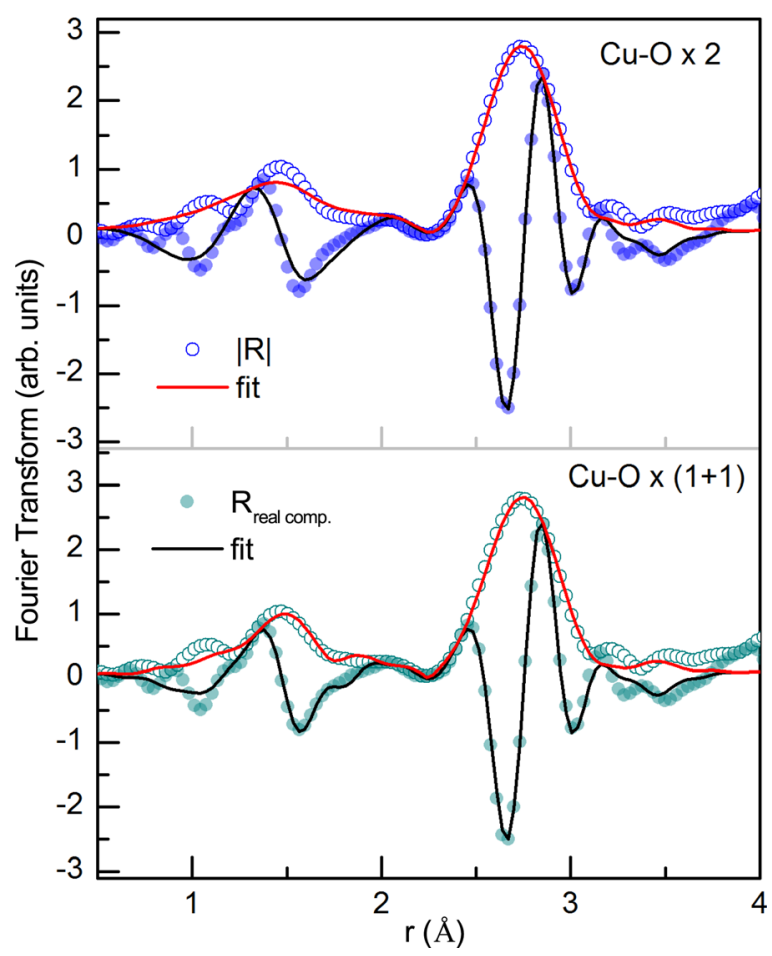

FIG. 7. Fitting of the magnitude and real component of Fourier transform of $\mathrm{Cu}$ K-edge EXAFS spectra, top panel: $\mathrm{Cu}-\mathrm{O}$ correlation with two equal bond distances and bottom panel: $\mathrm{Cu}-\mathrm{O}$ correlation with two different bond distances.

Owing to its site symmetry in the delafossite structure, the $\mathrm{Cu}$ ions have opportune freedom to vibrate in the planes perpendicular to the $\mathrm{Cu}-\mathrm{O}$ linear bonds aligned along the $c$-axis. This reflects as higher $\sigma^{2}$ and bond-distance values, not only of $\mathrm{Cu}-\mathrm{O} 1$, but $\mathrm{Cu}-\mathrm{Cu}$ as well, whereas the $\mathrm{Cr}$ ions are held within an edge sharing octahedral setting of $\mathrm{O}$ anions that provide less freedom to affect high disorder vibrations. The $\mathrm{Cu}-\mathrm{Cu}$ distance is perpendicular to the $c$-axis and can basically be seen as a measure of the $a$-axis parameter. However, the bond-distance value obtained from EXAFS analysis (of $300 \mathrm{~K}$ data), is slightly higher than the $a$ parameter obtained from the room temperature XRD analysis. This difference in the value for the same correlation obtained from XRD and EXAFS reflects the underlying local disorder that manifests in the form of correlations relating to $\mathrm{Cu}$ ions. Since EXAFS is a very local probe, it provides intricate changes within the unit cell with great detail.

The short and long bonds of $\mathrm{O}$ with $\mathrm{Cu}$ though distinct are quite intuitive. As already seen in the XRD profiles, there is a preferential orientation inherent in the structure with the unusually large $c$-axis. This indicates anisotropy in the $\mathrm{Cr}-\mathrm{O}_{6}$ octahedra linked by $\mathrm{Cu}-\mathrm{O}$ linear bonds. This effect gets manifested with $\mathrm{Ti}^{4+}$-substitution at the $\mathrm{Cr}^{3+}$ site, disturbing the cationic charge distribution in $\mathrm{CuCr}_{1-x} \mathrm{Ti}_{x} \mathrm{O}_{2}$. As confirmed from the XANES plots, the $3+$ charge state of $\mathrm{Cr}$ ions seems to remain intact across the Ti-substituted samples. On the other hand, a small variation seen in the edge energy of $\mathrm{Cu}$ absorption spectra highlights the changes occurring at the electronic level in the $\mathrm{Cu}-\mathrm{O}$ hybridization. $\mathrm{Cu}$ ions, however, maintain their $1+$ oxidation state. Besides, several experimental studies have reported anisotropy in the compressibility of copper based delafossite oxides, ${ }^{35}$ further augmenting our analysis. Pressure dependent Raman and EXAFS studies have in fact shown that at ambient pressure, the octahedral structures are distorted and become more regular with increasing hydrostatic pressure. ${ }^{36,37}$

\section{CONCLUSION}

$\mathrm{CuCrO}_{2}$ is a potential $\mathrm{Cu}$-based material actively pursued in $p$-type TCO research. The improvement in its electrical and/or optical conductivity is being sought by various methods, with substitution with other cations being one such approach. $\mathrm{CuCr}_{1-x} \mathrm{Ti}_{x} \mathrm{O}_{2}$ was studied here by substituting up to $10 \%$ of $\mathrm{Cr}$ ions with $\mathrm{Ti}$. The physical properties of all the prepared samples are discussed in view of the cation charge redistribution. The heat capacity measurement reflects the disrupted long range magnetic order caused due to local defect states created by non-magnetic Ti. Temperature variation of electrical resistivity indicates an activated type of charge transport with no significant change in the gap energy taking place due to Ti. Although UV-Vis spectroscopy does not indicate any appreciable change in the optical gap, it hints towards subtle changes taking place in the electronic structure. In contrast to a recent report claiming the $2+$ valence state of $\mathrm{Ti}$, a direct evidence for the $4+$ valence state is presented here using Ti K-edge XANES measurement. Besides, XANES measured at the $\mathrm{Cu}$ and $\mathrm{Cr} \mathrm{K}$-edge reaffirms the valence state of these transition metal cations and presents evidence for changing $\mathrm{Cu}-\mathrm{O}$ hybridization. The impact of cation charge redistribution is also seen on the local crystal structure as determined quantitatively from the EXAFS analysis. The current study is an extension towards understanding the $p$-type delafossite materials in general and the specific efforts made towards appreciation of electrical conductivity of $\mathrm{CuCrO}_{2}$.

\section{ACKNOWLEDGMENTS}

This work was supported by the Department of Science and Technology (DST), New Delhi (Grant No. SR/S2/CMP0109/2012). Parts of this research were carried out at Petra III at the DESY, a member of the Helmholtz Association (HGF), Germany. We would like to thank Edmund Welter and Ruidy Nemausat for the assistance in using beamline P65. P.A.B. thanks the DST for travel support to Germany. Parts of XANES measurement were carried out at INDUS-II RRCAT, Indore. We thank Dr. S. N. Jha and Dr. Parasmani Rajput for their help in using BL-09. We thank Mr. Devendra Buddhikot for help in the heat capacity and resistivity measurements. M.K.M. thanks the Ministry of Human Resource Development (MHRD), Government of India, for the teaching assistantship.

${ }^{1}$ O. N. Mryasov and A. J. Freeman, Phys. Rev. B 64, 233111 (2001).

${ }^{2}$ J. C. Park, H.-N. Lee, and S. Im, ACS Appl. Mater. Interfaces 5, 6990 (2013).

${ }^{3}$ G. Hautier, A. Miglio, G. Ceder, G.-M. Rignanese, and X. Gonze, Nat. Commun. 4, 2292 (2013).

${ }^{4}$ A. B. Kehoe, E. Arca, D. O. Scanlon, I. V. Shvets, and G. W. Watson, J. Phys.: Condens. Matter 28, 125501 (2016). 
${ }^{5}$ K. H. L. Zhang, Y. Du, A. Papadogianni, O. Bierwagen, S. Sallis, L. F. J. Piper, M. E. Bowden, V. Shutthanandan, P. V. Sushko, and S. A. Chambers, Adv. Mater. 27, 5191 (2015).

${ }^{6}$ A. R. Nagaraja, K. H. Stone, M. F. Toney, H. Peng, S. Lany, and T. O. Mason, Chem. Mater. 26, 4598 (2014).

${ }^{7}$ F. A. Benko and F. P. Koffyberg, Mater. Res. Bull. 21, 753 (1986).

${ }^{8}$ D. O. Scanlon and G. W. Watson, J. Mater. Chem. 21, 3655 (2011)

${ }^{9}$ M. Poienar, F. Damay, C. Martin, V. Hardy, A. Maignan, and G. Andre, Phys. Rev. B 79, 014412 (2009).

${ }^{10}$ E. Pachoud, K. Singh, Y. Breard, C. Martin, G. Andre, V. Hardy, C. Simon, and A. Maignan, Phys. Rev. B 86, 054437 (2012).

${ }^{11}$ S. Luo, K. F. Wang, S. Z. Li, X. W. Dong, Z. B. Yan, H. L. Cai, and J. Liu, Appl. Phys. Lett. 94, 172504 (2009).

${ }^{12}$ M. Amami, F. Jlaiel, P. Strobel, and A. B. Salah, Mater. Res. Bull. 46, 1729 (2011).

${ }^{13}$ D. Li, X. Fang, W. Dong, Z. Deng, R. Tao, S. Zhou, J. Wang, T. Wang, Y. Zhao, and X. Zhu, J. Phys. D: Appl. Phys. 42, 055009 (2009).

${ }^{14}$ J. Li, A. W. Sleight, C. Y. Jones, and B. H. Toby, J. Solid State Chem. 178, 285 (2005).

${ }^{15}$ S. I. Ahmed, G. Dalba, P. Fornasini, M. Vaccari, F. Rocca, A. Sanson, J. Li, and A. W. Sleight, Phys. Rev. B 79, 104302 (2009).

${ }^{16}$ R. Nagarajan, N. Duan, M. K. Jayaraj, J. Li, K. A. Vanaja, A. Yokochi, A. Draeseke, J. Tate, and A. W. Sleight, Int. J. Inorg. Mater. 3, 265 (2001).

${ }^{17}$ R. Nagarajan, A. D. Draeseke, A. W. Sleight, and J. Tate, J. Appl. Phys. 89, 8022 (2001).

${ }^{18}$ T. Elkhouni, M. Amami, P. Strobel, and A. B. Salah, J. Supercond. Novel Magn. 26, 2795 (2013)

${ }^{19}$ R. Li, Z. Qu, and Y. Zhang, J. Am. Ceram. Soc. 98, 2503 (2015).

${ }^{20}$ J. Rodriguez-Carvajal, Physica B 192, 55 (1993).

${ }^{21}$ B. Ravel and M. Newville, J. Synchrotron Radiat. 12, 537 (2005).

${ }^{22}$ S. Zhou, X. Fang, Z. Deng, D. Li, W. Dong, R. Tao, G. Meng, T. Wang, and X. Zhu, J. Cryst. Growth 310, 5375 (2008).
${ }^{23}$ J. B. Goodenough, Phys. Rev. 117, 1442 (1960).

${ }^{24}$ K. Motida and S. Miyahara, J. Phys. Soc. Jpn. 28, 1188 (1970).

${ }^{25}$ M. K. Majee, P. A. Bhobe, and A. K. Nigam, AIP Conf. Proc. 1731, 130022 (2016).

${ }^{26}$ H. Kadowaki, H. Kikuchi, and Y. Ajiro, J. Phys.: Condens. Matter 2, 4485 (1990).

${ }^{27}$ T. Okuda, Y. Beppu, Y. Fujii, T. Onoe, N. Terada, and S. Miyasaka, Phys. Rev. B 77, 134423 (2008).

${ }^{28}$ T. Okuda, N. Jufuku, S. Hidaka, and N. Terada, Phys. Rev. B 72, 144403 (2005).

${ }^{29}$ H. Hiraga, T. Makino, T. Fukumura, H. Weng, and M. Kawasaki, Phys. Rev. B 84, 041411 (2011).

${ }^{30}$ J. Tauc, R. Gigorovici, and A. Vancu, Phys. Status Solidi 15, 627 (1966).

${ }^{31}$ D. Shin, J. S. Foord, R. G. Egdell, and A. Walsh, J. Appl. Phys. 112, 113718 (2012).

${ }^{32}$ T. Arnold, D. J. Payne, A. Bourlange, J. P. Hu, and R. G. Egdell, Phys. Rev. B 79, 075102 (2009).

${ }^{33}$ S. Maiti, J. Llorca, M. Dominguez, S. Colussi, A. Trovarelli, K. R. Priolkar, G. Aquilanti, and A. Gayen, J. Power Sources 304, 319 (2016).

${ }^{34}$ T. Yokobori, M. Okawa, K. Konishi, R. Takei, K. Katayama, S. Oozono, T. Shinmura, T. Okuda, H. Wadati, E. Sakai, K. Ono, H. Kumigashira, M. Oshima, T. Sugiyama, E. Ikenaga, N. Hamada, and T. Saitoh, Phys. Rev. B 87, 195124 (2013).

${ }^{35}$ A. B. Garg, A. K. Mishra, K. K. Pandey, and S. M. Sharma, J. Appl. Phys. 116, 133514 (2014).

${ }^{36}$ J. P. Porres, A. Segura, C. Ferrer-Roca, D. Martnez-Garc, J. A. Sans, J. P. Itie, A. Polian, F. Baudelet, E. M. A. Munoz, P. Rodrguez-Hernandez, and P. Munsch, Phys. Rev. B 69, 024109 (2004).

${ }^{37}$ J. P. Porres, A. Segura, E. Martnez, A. M. Saitta, A. Polian, J. C. Chervin, and B. Canny, Phys. Rev. B 72, 064301 (2005). 